\title{
Rural-urban Correlates of Modern Contraceptives Utilization Among Adolescents in Zambia: a National Cross-sectional Survey
}

Quraish Sserwanja ( $\nabla$ qura661@gmail.com )

GOAL https://orcid.org/0000-0003-0576-4627

Milton W. Musaba

Busitema University

Linet M. Mutisya

Swedish Organization for Global Health

David Mukunya

Busitema University

\section{Research Article}

Keywords: Modern contraceptive, Rural-urban correlates, contraceptives utilization, cross-sectional survey, Zambia

Posted Date: March 18th, 2021

DOl: https://doi.org/10.21203/rs.3.rs-321775/v1

License: (9) This work is licensed under a Creative Commons Attribution 4.0 International License. Read Full License 


\section{Abstract}

Background: Modern contraceptive use among adolescents is low despite the adverse effects of adolescent pregnancies and births. Understanding the predictors of modern contraceptive use in different settings is key to design effective context-specific interventions. We aimed to determine factors associated with modern contraceptives use among adolescents in rural and urban settings of Zambia.

Methods: We analyzed data from 2018 Zambia demographic and health survey (ZDHS) focusing on adolescent girls aged 15-19 years. We conducted multilevel logistic regression using SPSS version 25 to examine rural-urban variations in factors associated with modern contraceptive utilization.

Results: Overall, $12.0 \%$ (360/3000, 95\% Cl: 10.9-13.2) of adolescents in Zambia were using modern contraceptives. Use of modern contraceptives was higher in rural areas at 13.7\% (230/1677, 95\% Cl: 12.115.3) compared to $9.8 \%(130 / 1323,95 \% \mathrm{Cl}: 8.3-11.6)$ in urban areas. In the rural areas, having a child $(\mathrm{aOR}=13.46 ; 95 \% \mathrm{Cl} 8.28$ to 21.90$)$, marriage $(\mathrm{aOR}=1.97 ; 95 \% \mathrm{Cl} 1.25$ to 3.08$)$, older age (being 19 years) $(\mathrm{aOR}=3.97 ; 95 \% \mathrm{Cl} 1.51$ to 10.1$)$ and belonging to the richest wealth quintile $(\mathrm{aOR}=3.01 ; 95 \% \mathrm{Cl}$ 1.06 to 8.58 ) were positively associated with contraceptive utilization. In the urban areas, older age (being 19 years) (aOR $=4.80 ; 95 \% \mathrm{Cl} 1.55$ to 14.84$)$ and having a child (aOR $=18.52 ; 95 \% \mathrm{Cl} 9.50$ to 36.14 ) were the only factors positively associated with modern contraceptive utilization.

Conclusions: Having shown that some factors (age and having a child) were associated with modern contraceptive use in both rural and urban areas while some were only significant in rural areas (province, marital status and wealth index), indicates that the urban-rural differences in modern contraceptives use are both due to differences in the levels and nature or type of determinants. Therefore, interventions aiming to increase contraceptive utilization should be context specific.

\section{Plain English Summary}

Purpose: Modern contraceptive use among adolescents is low despite the negative outcomes of adolescent pregnancies and births. Understanding the factors associated with modern contraceptive use in rural and urban settings is key to design effective context-specific interventions. This paper explains the rural-urban differences in modern contraceptives utilization and associated factors among adolescents in Zambia.

Methods: We analyzed data from the 2018 Zambia demographic and health survey (ZDHS) focusing on adolescent girls aged 15-19 years. Adolescents were asked if they were currently using any modern contraceptive method.

Results: Out of the total 3,000 adolescents, $12.0 \%$ were using modern contraceptives. Use of modern contraceptives was higher in rural areas at $13.7 \%$ compared to $9.8 \%$ in urban areas. In the rural areas, adolescents were more likely to use modern contraception if they had ever given birth, were married, were 
older (being 19 years) and belonged to the richest households. In Urban areas, adolescents were more likely to use modern contraception if they had ever given birth and were older (being 19 years).

Conclusions: Programs wanting to help adolescents in Zambia to prevent pregnancy and sexually transmitted infections through use of contraceptives should ensure that during the designing of the interventions, these rural-urban differences are put into consideration.

\section{Background}

Globally, adolescent fertility rate is high with their birth rate standing at 44 births per 1000 women [1]. Africa faces the highest burden of adolescent fertility with sub-Saharan Africa standing at 101 births per 1000 females [1]. Non-use of a modern contraception method contributes to over $90 \%$ of annual unplanned pregnancies among adolescents in sub-Saharan Africa, Latin America and the Caribbean, and South Central and Southeast Asia [1].

Adolescent childbearing is associated with adverse health risks such as; increased maternal mortality and morbidity, disability such as obstetric fistula, and sexually transmitted infections [2]. These health complications are the second leading cause of mortality among adolescents [2]. Furthermore, babies born to adolescent mothers are at an increased risk of higher perinatal mortality and low birth weight [2, 3]. Despite the adverse effects of adolescent pregnancies and births, contraceptive use among adolescents in Africa is low $[2,4,5]$. In addition to the negative health outcomes, adolescent childbirths and STIs have been associated with adverse socio-economic consequences such as; poverty, school dropout and subsequent lower educational attainment which affects their personal development $[1,6]$.

Promoting use of modern contraceptives in this age group is a priority intervention that will ensure improvement of pregnancy health-related outcomes $[7,8]$. Due to the heterogeneous nature of the subSaharan region, sub-regional variations exist in contraceptive use among young women [9]. Despite the various interventions and policies to promote modern contraceptives utilization among young women in Sub-Saharan Africa, the utilization rate has remained low $[2,10,11]$. This could partly be attributed to generic interventions and policies that are not adapted to local settings [10].

Zambia's adolescent contraceptive use is low despite high universal knowledge of at least one modern contraceptive method [2]. Information on the predictors of the rural-urban differentials in uptake of modern contraceptive utilization among female adolescents is relevant since policies, programs, and interventions that are necessary to improve modern contraceptive uptake may differ in rural and urban areas. Although disparities in the rates of utilization of contraceptives between urban and rural adolescents have been documented [2,12], information on factors responsible for these differences has not been adequately explained. It is important to further understand these factors when stratifying by rural-urban place of residence among adolescents. Understanding the various predictors of modern contraceptive uptake in different settings is key to designing effective context-specific interventions tailored to the needs of each setting. Therefore, we aimed to determine factors associated with modern contraceptive utilization among adolescents in Zambia stratified by rural-urban place of residence. 


\section{Material And Methods}

\section{Study Data}

We conducted a secondary data analysis using the 2018 Zambia Demographic and Health Survey (ZDHS) dataset after obtaining permission from the MEASURE DHS project. Demographic health surveys (DHS) are national surveys that are conducted periodically in low and middle income countries (LMICs) standardized to enable comparisons among the different countries [13, 14]. The 2018 ZDHS is the sixth in a series of demographic and health Surveys with the previous surveys conducted in 1992, 1996, 200102, 2007, and 2013-14 [13].The 2018 ZDHS data were collected between $18^{\text {th }}$ July 2018 and $24^{\text {th }}$ January 2019 [13]. The ZDHS is designed to provide up-to-date information on health indicators using household, women's, men's and biomarker questionnaires [13]. The data used in this study was collected using the women's questionnaire. Female adolescents were asked if they were currently using any method of modern contraception [13].

\section{Study Sampling and Participants}

The 2018 ZDHS was implemented by the Zambia Statistics Agency in partnership with the ministry of health; the University Teaching Hospital Virology Laboratory (UTH-VL); and the department of population studies at the University of Zambia (UNZA) [13]. The ZDHS used two-stage systematic sampling to select participants from households nested in clusters (enumeration areas) across the all the provinces of Zambia [13]. Women aged 15-49 years who were either permanent residents or visitors who had stayed in the selected households the night before the survey were eligible for interviews with a total of 13,683 women being interviewed [13]. Of these, a weighted sample of 3,000 (1,677 rural and 1,323 urban) were adolescents aged between 15 and 19 years who had consented and were interviewed. Written informed consent was provided by all participants of the survey. Written permission to access the whole ZDHS database was obtained through DHS program [15]. Flow diagram for the sampling process and the STROBE checklist are included in supplementary files 1 and 2 respectively. A detailed explanation of the sampling process is available in the ZDHS 2018 report [13].

\section{Outcome Variables}

Utilization of any method of modern contraceptive method (sterilization, injectable, intrauterine devices (IUDs), contraceptive pills, implants, condoms, the standard days method, lactational amenorrhea, and emergency contraception) [13] was coded as one (1) while non-utilization was coded as zero (0).

\section{Independent variables}

This study included determinants of modern contraceptives utilization basing on evidence from available literature and data [16-18]. We included twelve explanatory variables in the analysis. Wealth index is a measure of relative household economic status and was calculated by DHS from information on household asset ownership using Principal Component [13]. Independent variables were categorized into; 


\section{Individual characteristics}

Level of education (no education, primary and post primary), age $(15,16,17,18$ and 19), marital status (married and not married), having a child (yes and no), working status (working and not working), exposure to television (TV), radio and newspapers (yes and no).

\section{Household characteristics}

Wealth index of household (categorized into quintiles: richest, richer, middle poorer and poorest), province of residence (all the 10 provinces of Zambia), number of household members (less than 6 and 6 and above) and sex of household head (female and male).

\section{Statistical Analysis}

To account for the unequal probability sampling in different strata [19] and to ensure representativeness of the survey results at all levels, we used sample weights [20]. Furthermore, to account for the multistage cluster study design, complex sample analysis was performed using SPSS version 25.0 statistical software. Proportions were tabulated for each of the categorical independent variable. Bivariable logistic regression was done to the association of each exposure with the outcome variable and we presented crude odds ratio (COR), 95\% confidence interval $(\mathrm{Cl})$ and p-values. Independent variables found significant at bivariable level ( $p$-value $<0.25$ ) were included in the final multivariable logistic regression model. Two separate models for urban and rural samples were fitted with the first model (Rural Model) fitted to identify the predictors of modern contraceptive utilization for rural adolescents and the second model (Urban Model) to identify predictors among urban adolescents. The independent variables used for both rural and urban adolescents were the same to enable a comparison between both areas. Adjusted odds ratios (AOR), 95\% Confidence Intervals (Cl) and p-values were calculated with statistical significance level set at $\mathrm{p}$-value $<0.05$. All variables in the model were assessed for collinearity, which was considered present if the variables had a variance inflation factor (VIF) greater than 10.

\section{Results}

Table 1 shows a comparison of selected background characteristics of female adolescents in rural and urban Zambia. Rural areas had more participants $(1,677)$ compared to urban areas $(1,323)$. Remarkable differences were observed in exposure to mass media with $19.6 \%$ and $16.3 \%$ in rural areas exposed to TV and newspapers respectively compared to $72.9 \%$ (TV) and 30.5\% (newspapers) in urban areas.

Furthermore, $22.5 \%$ of rural adolescents were working compared to $11 \%$ in urban areas, $21.1 \%$ in rural areas were married compared to $6.3 \%$ in urban areas and $38.9 \%$ had post-primary education in rural areas compared to $73 \%$ in urban areas. Almost half $(48.3 \%)$ of the adolescents in urban areas belonged to the richest wealth quintile compared to $4.2 \%$ in rural areas. More detailed characteristics of study participants are shown in Table 1. Overall, $12.0 \%$ (360/3000, 95\% Cl: 10.9-13.2) of the female adolescents in Zambia were utilizing modern contraceptives. Utilization of modern contraceptives was higher in rural areas at $13.7 \%$ (230/1677, $95 \%$ Cl: $12.1-15.3)$ compared to $9.8 \%$ (130/1323, 95\% Cl: 8.3-11.6) in urban areas. 
Table 1

Rural-Urban background characteristics of adolescents as per ZDHS 2018

\begin{tabular}{|c|c|c|c|c|}
\hline Characteristics & Rural N = 1677 & $\%$ & Urban $N=1323$ & $\%$ \\
\hline \multicolumn{5}{|c|}{ Household number } \\
\hline Less than 6 & 527 & 31.4 & 455 & 34.4 \\
\hline 6 and above & 1150 & 68.6 & 868 & 65.6 \\
\hline \multicolumn{5}{|c|}{ Sex of household head } \\
\hline Female & 413 & 24.6 & 421 & 31.8 \\
\hline Male & 1264 & 75.4 & 902 & 68.2 \\
\hline \multicolumn{5}{|l|}{ Provinces } \\
\hline Central & 195 & 11.6 & 102 & 7.7 \\
\hline Copper belt & 67 & 4.0 & 424 & 32.0 \\
\hline Eastern & 295 & 17.6 & 47 & 3.5 \\
\hline Luapula & 191 & 11.4 & 62 & 4.7 \\
\hline Lusaka & 60 & 3.6 & 415 & 31.4 \\
\hline Muchinga & 156 & 9.3 & 35 & 2.6 \\
\hline Northern & 196 & 11.7 & 53 & 4.0 \\
\hline North Western & 146 & 8.7 & 41 & 3.1 \\
\hline Southern & 232 & 13.8 & 95 & 7.2 \\
\hline Western & 139 & 8.3 & 50 & 3.8 \\
\hline \multicolumn{5}{|c|}{ Exposure to Newspapers } \\
\hline Yes & 274 & 16.3 & 403 & 30.5 \\
\hline No & 1403 & 83.7 & 920 & 69.5 \\
\hline \multicolumn{5}{|l|}{ Working status } \\
\hline Not working & 1299 & 77.5 & 1178 & 89.0 \\
\hline Working & 378 & 22.5 & 145 & 11.0 \\
\hline \multicolumn{5}{|l|}{ Marital status } \\
\hline Not Married & 1323 & 78.9 & 1240 & 93.7 \\
\hline Married & 354 & 21.1 & 83 & 6.3 \\
\hline
\end{tabular}




\begin{tabular}{|c|c|c|c|c|}
\hline Characteristics & Rural N = 1677 & $\%$ & Urban $N=1323$ & $\%$ \\
\hline No Education & 88 & 5.2 & 11 & 0.8 \\
\hline Primary Education & 937 & 55.8 & 346 & 26.2 \\
\hline Post Primary Education & 653 & 38.9 & 966 & 73.0 \\
\hline \multicolumn{5}{|l|}{ Wealth Index } \\
\hline Poorest & 502 & 29.9 & 8 & 0.6 \\
\hline Poorer & 511 & 30.5 & 30 & 2.2 \\
\hline Middle & 439 & 26.2 & 146 & 11.0 \\
\hline Richer & 154 & 9.2 & 501 & 37.9 \\
\hline Richest & 70 & 4.2 & 639 & 48.3 \\
\hline \multicolumn{5}{|l|}{ Age } \\
\hline 15 & 397 & 23.6 & 256 & 19.4 \\
\hline 16 & 306 & 18.3 & 224 & 16.9 \\
\hline 17 & 287 & 17.1 & 265 & 20.1 \\
\hline 18 & 415 & 24.7 & 308 & 23.2 \\
\hline 19 & 272 & 16.1 & 270 & 20.4 \\
\hline \multicolumn{5}{|l|}{ Has a child or children } \\
\hline No & 1175 & 70.0 & 1102 & 83.3 \\
\hline Yes & 502 & 30.0 & 221 & 16.7 \\
\hline \multicolumn{5}{|l|}{ Exposure to Radio } \\
\hline Yes & 584 & 34.8 & 710 & 53.6 \\
\hline No & 1093 & 65.2 & 614 & 46.4 \\
\hline \multicolumn{5}{|l|}{ Exposure to TV } \\
\hline Yes & 329 & 19.6 & 965 & 72.9 \\
\hline No & 1348 & 80.4 & 358 & 27.1 \\
\hline \multicolumn{5}{|l|}{ Contraception use } \\
\hline Yes & 230 & 13.7 & 130 & 9.8 \\
\hline No & 1447 & 86.3 & 1193 & 90.2 \\
\hline
\end{tabular}

Predictors of rural and urban utilization of modern contraceptives 
Table 2 presents results of multivariable logistic regression analysis showing predictors of rural and urban utilization of contraceptives among rural and urban female adolescents. Our analysis revealed that older age (19 years) and history of childbirth have significant positive association with modern contraceptive utilization among adolescents from both regions of residence. In the rural areas, having a child ( $\mathrm{aOR}=13.46 ; 95 \% \mathrm{Cl} 8.28$ to 21.90 ), being married ( $\mathrm{aOR}=1.97 ; 95 \% \mathrm{Cl} 1.25$ to 3.08 ), being older at 19 years $(\mathrm{aOR}=3.97 ; 95 \% \mathrm{Cl} 1.51$ to 10.1$)$ and belonging to the richest wealth quintile $(\mathrm{aOR}=3.01 ; 95 \% \mathrm{Cl}$ 1.06 to 8.58 ) were positively associated with contraceptive utilization. Furthermore, adolescents in the Northern ( $\mathrm{aOR}=0.28 ; 95 \% \mathrm{Cl} 0.10$ to 0.76 ) and Luapula ( $\mathrm{aOR}=0.36 ; 95 \% \mathrm{Cl} 0.15$ to 0.86 ) provinces were less likely to utilize contraceptives compared to those in Western province.

In the urban areas, older age at 19 years $(\mathrm{aOR}=4.80 ; 95 \% \mathrm{Cl} 1.55$ to 14.84$)$ and having a child (aOR $=$ $18.52 ; 95 \% \mathrm{Cl} 9.50$ to 36.14 ) were the only factors positively associated with modern contraceptive utilization. 
Table 2

Predictors of rural urban utilization of contraceptives among female adolescents in Zambia

\begin{tabular}{|c|c|c|c|c|c|c|}
\hline Characteristics & $\begin{array}{l}\text { Rural COR } \\
(95 \% \mathrm{Cl})\end{array}$ & $\begin{array}{l}\mathrm{P} \text { - } \\
\text { value }\end{array}$ & $\begin{array}{l}\text { Rural AOR } \\
(95 \% \mathrm{Cl})\end{array}$ & $\begin{array}{l}\text { Urban COR } \\
(95 \% \mathrm{Cl})\end{array}$ & $\begin{array}{l}\mathrm{P} \text { - } \\
\text { value }\end{array}$ & $\begin{array}{l}\text { Urban AOR } \\
(95 \% \mathrm{Cl})\end{array}$ \\
\hline $\begin{array}{l}\text { Household } \\
\text { number }\end{array}$ & & $\begin{array}{l}< \\
0.001\end{array}$ & & & 0.544 & \\
\hline 6 and above & 1 & & 1 & 1 & & \\
\hline Less than 6 & $\begin{array}{l}2.42(1.79- \\
3.27)\end{array}$ & & $\begin{array}{l}1.17(0.75- \\
1.84)\end{array}$ & $\begin{array}{l}1.19(0.68- \\
2.10)\end{array}$ & & \\
\hline $\begin{array}{l}\text { Sex of family } \\
\text { head }\end{array}$ & & 0.356 & & & 0.078 & \\
\hline Male & 1 & & & 1 & & 1 \\
\hline Female & $\begin{array}{l}0.83(0.56- \\
1.24)\end{array}$ & & & $\begin{array}{l}0.60(0.34- \\
1.06)\end{array}$ & & $\begin{array}{l}0.59(0.28- \\
1.22)\end{array}$ \\
\hline Provinces & & $<.001$ & & & 0.882 & \\
\hline Western & 1 & & 1 & 1 & & \\
\hline Copperbelt & $\begin{array}{l}0.43(0.19- \\
0.99)\end{array}$ & & $\begin{array}{l}0.54(0.19- \\
1.58)\end{array}$ & $\begin{array}{l}0.87(0.32- \\
2.34)\end{array}$ & & \\
\hline Eastern & $\begin{array}{l}0.89(0.49- \\
1.62)\end{array}$ & & $\begin{array}{l}0.72(0.31- \\
1.68)\end{array}$ & $\begin{array}{l}0.71(0.17- \\
3.00)\end{array}$ & & \\
\hline Luapula & $\begin{array}{l}0.37(0.19- \\
0.74)\end{array}$ & & $\begin{array}{l}0.36(0.15- \\
0.86)\end{array}$ & $\begin{array}{l}0.54(0.17- \\
1.73)\end{array}$ & & \\
\hline Lusaka & $\begin{array}{l}0.71(0.31- \\
1.62)\end{array}$ & & $\begin{array}{l}0.76(0.28- \\
2.03)\end{array}$ & $\begin{array}{l}0.76(0.26- \\
2.20)\end{array}$ & & \\
\hline Muchinga & $\begin{array}{l}0.51(0.25- \\
1.04)\end{array}$ & & $\begin{array}{l}0.47(0.18- \\
1.19)\end{array}$ & $\begin{array}{l}0.90(0.20- \\
3.99)\end{array}$ & & \\
\hline Northern & $\begin{array}{l}0.28(0.12- \\
0.65)\end{array}$ & & $\begin{array}{l}0.28(0.10- \\
0.76)\end{array}$ & $\begin{array}{l}0.55(0.14- \\
2.23)\end{array}$ & & \\
\hline North Western & $\begin{array}{l}1.39(0.76- \\
2.56)\end{array}$ & & $\begin{array}{l}1.73(0.66- \\
4.53)\end{array}$ & $\begin{array}{l}1.16(0.32- \\
4.25)\end{array}$ & & \\
\hline Southern & $\begin{array}{l}0.57(0.29- \\
1.14)\end{array}$ & & $\begin{array}{l}0.52(0.19- \\
1.42)\end{array}$ & $\begin{array}{l}0.48(0.15- \\
1.55)\end{array}$ & & \\
\hline Central & $\begin{array}{l}0.71(0.34- \\
1.50)\end{array}$ & & $\begin{array}{l}0.69(0.27- \\
1.78)\end{array}$ & $\begin{array}{l}0.92(0.33- \\
2.56)\end{array}$ & & \\
\hline $\begin{array}{l}\text { Newspapers } \\
\text { exposure }\end{array}$ & & 0.518 & & & 0.272 & \\
\hline
\end{tabular}

bold = Significant at $p$-value $<0.05$ 


\begin{tabular}{|c|c|c|c|c|c|c|}
\hline Characteristics & $\begin{array}{l}\text { Rural COR } \\
(95 \% \mathrm{Cl})\end{array}$ & $\begin{array}{l}\mathrm{P}- \\
\text { value }\end{array}$ & $\begin{array}{l}\text { Rural AOR } \\
(95 \% \mathrm{Cl})\end{array}$ & $\begin{array}{l}\text { Urban COR } \\
(95 \% \mathrm{Cl})\end{array}$ & $\begin{array}{l}\mathrm{P}- \\
\text { value }\end{array}$ & $\begin{array}{l}\text { Urban AOR } \\
(95 \% \mathrm{Cl})\end{array}$ \\
\hline No & 1 & & & 1 & & \\
\hline Yes & $\begin{array}{l}0.87(0.56- \\
1.34)\end{array}$ & & & $\begin{array}{l}0.75(0.44- \\
1.26)\end{array}$ & & \\
\hline Working status & & $<.001$ & & & 0.029 & \\
\hline Not working & 1 & & 1 & 1 & & 1 \\
\hline Working & $\begin{array}{l}1.89(1.39- \\
2.56)\end{array}$ & & $\begin{array}{l}0.97(0.68- \\
1.40)\end{array}$ & $\begin{array}{l}2.13(1.08- \\
4.21)\end{array}$ & & $\begin{array}{l}0.76(0.24- \\
2.43)\end{array}$ \\
\hline Marital status & & $<.001$ & & & $<.001$ & \\
\hline Not Married & 1 & & 1 & 1 & & 1 \\
\hline Married & $\begin{array}{l}7.32(5.26- \\
10.18)\end{array}$ & & $\begin{array}{l}1.97(1.25- \\
3.08)\end{array}$ & $\begin{array}{l}8.19(4.06- \\
16.53)\end{array}$ & & $\begin{array}{l}1.28(0.58- \\
2.80)\end{array}$ \\
\hline Education Level & & 0.271 & & & 0.262 & \\
\hline No Education & 1 & & & 1 & & \\
\hline $\begin{array}{l}\text { Primary } \\
\text { Education }\end{array}$ & $\begin{array}{l}1.49(0.70- \\
3.14)\end{array}$ & & & $\begin{array}{l}3.44(0.49- \\
24.02)\end{array}$ & & \\
\hline $\begin{array}{l}\text { Post Primary } \\
\text { Education }\end{array}$ & $\begin{array}{l}1.22(0.56- \\
2.62)\end{array}$ & & & $\begin{array}{l}2.45(0.36- \\
16.83)\end{array}$ & & \\
\hline Wealth Index & & 0.061 & & & 0.010 & \\
\hline Poorest & 1 & & 1 & 1 & & 1 \\
\hline Poorer & $\begin{array}{l}0.89(0.63- \\
1.26)\end{array}$ & & $\begin{array}{l}1.18(0.72- \\
1.93)\end{array}$ & $\begin{array}{l}0.73(0.14- \\
3.99)\end{array}$ & & $\begin{array}{l}0.21(0.01- \\
3.85)\end{array}$ \\
\hline Middle & $\begin{array}{l}0.63(0.42- \\
0.95)\end{array}$ & & $\begin{array}{l}1.06(0.61- \\
1.83)\end{array}$ & $\begin{array}{l}1.44(0.24- \\
8.75)\end{array}$ & & $\begin{array}{l}0.61(0.03- \\
14.11)\end{array}$ \\
\hline Richer & $\begin{array}{l}0.47(0.23- \\
0.97)\end{array}$ & & $\begin{array}{l}0.79(0.38- \\
1.66)\end{array}$ & $\begin{array}{l}1.35(0.22- \\
8.19)\end{array}$ & & $\begin{array}{l}1.09(0.04- \\
26.85)\end{array}$ \\
\hline Richest & $\begin{array}{l}0.48(0.20- \\
1.17)\end{array}$ & & $\begin{array}{l}3.01(1.06- \\
8.58)\end{array}$ & $\begin{array}{l}0.49(0.07- \\
3.08)\end{array}$ & & $\begin{array}{l}1.07(0.03- \\
29.54)\end{array}$ \\
\hline Age & & $<.001$ & & & $<.001$ & \\
\hline
\end{tabular}

bold = Significant at $p$-value $<0.05$ 


\begin{tabular}{|c|c|c|c|c|c|c|}
\hline Characteristics & $\begin{array}{l}\text { Rural COR } \\
(95 \% \mathrm{Cl})\end{array}$ & $\begin{array}{l}\mathrm{P} \text { - } \\
\text { value }\end{array}$ & $\begin{array}{l}\text { Rural AOR } \\
(95 \% \mathrm{Cl})\end{array}$ & $\begin{array}{l}\text { Urban COR } \\
(95 \% \mathrm{Cl})\end{array}$ & $\begin{array}{l}\mathrm{P} \text { - } \\
\text { value }\end{array}$ & $\begin{array}{l}\text { Urban AOR } \\
(95 \% \mathrm{Cl})\end{array}$ \\
\hline 15 & 1 & & 1 & 1 & & 1 \\
\hline 16 & $\begin{array}{l}2.69(0.97- \\
7.41)\end{array}$ & & $\begin{array}{l}1.76(0.63- \\
4.98)\end{array}$ & $\begin{array}{l}0.54(0.18- \\
2.11)\end{array}$ & & $\begin{array}{l}0.29(0.07- \\
1.29)\end{array}$ \\
\hline 17 & $\begin{array}{l}5.34(2.11- \\
13.56)\end{array}$ & & $\begin{array}{l}2.09(0.80- \\
5.51)\end{array}$ & $\begin{array}{l}4.43(1.23- \\
15.94)^{-1}\end{array}$ & & $\begin{array}{l}1.65(0.37- \\
7.40)\end{array}$ \\
\hline 18 & $\begin{array}{l}9.83(3.94- \\
24.49)\end{array}$ & & $\begin{array}{l}2.55(0.96- \\
6.74)\end{array}$ & $\begin{array}{l}6.84(2.48- \\
18.88)\end{array}$ & & $\begin{array}{l}1.84(0.62- \\
5.46)\end{array}$ \\
\hline 19 & $\begin{array}{l}20.28(8.38- \\
49.08)\end{array}$ & & $\begin{array}{l}3.97(1.51- \\
10.1)\end{array}$ & $\begin{array}{l}17.61(7.02- \\
44.11)\end{array}$ & & $\begin{array}{l}4.80(1.55- \\
14.84)\end{array}$ \\
\hline Gave Birth & & $\begin{array}{l}< \\
0.001\end{array}$ & & & $\begin{array}{l}< \\
0.001\end{array}$ & \\
\hline No & 1 & & 1 & 1 & & 1 \\
\hline Yes & $\begin{array}{l}23.13(14.83- \\
36.07)\end{array}$ & & $\begin{array}{l}13.46(8.28- \\
21.90\end{array}$ & $\begin{array}{l}25.85(13.13- \\
50.88\end{array}$ & & $\begin{array}{l}18.52(9.50- \\
36.14\end{array}$ \\
\hline $\begin{array}{l}\text { Exposure to } \\
\text { Radio }\end{array}$ & & 0.990 & & & 0.726 & \\
\hline No & 1 & & & 1 & & \\
\hline Yes & $\begin{array}{l}1.00(0.75- \\
1.34)\end{array}$ & & & $\begin{array}{l}0.92(0.56- \\
1.50)\end{array}$ & & \\
\hline Exposure to TV & & 0.714 & & & $<.001$ & \\
\hline No & 1 & & & 1 & & 1 \\
\hline Yes & $\begin{array}{l}0.93(0.64- \\
1.36)\end{array}$ & & & $\begin{array}{l}0.36(0.23- \\
0.57)\end{array}$ & & $\begin{array}{l}0.51(0.22- \\
1.19)\end{array}$ \\
\hline
\end{tabular}

\section{Discussion}

This study investigated the factors associated with modern contraceptives utilization among adolescents in rural and urban settings of Zambia. Utilization of modern contraceptives was higher in rural areas at $13.7 \%$ (230/1,677, 95\% Cl: $12.1-15.3)$ compared to $9.8 \%(130 / 1,323,95 \% \mathrm{Cl}: 8.3-11.6)$ in urban areas. This could partly be attributed to the fact that rural areas have more married $(21.1 \%)$ and less nulliparous (70\%) adolescents compared to urban areas whose $6.3 \%$ and $83.3 \%$ of adolescents are married and nulliparous respectively. Married adolescents and those who have had a child have been shown to be more likely to utilize modern contraceptives. Our study showed that contraceptive utilization in Zambia is lower than that of the sub-Saharan region average, Europe, Latin America and United States of America 
(USA) $[9,10,21-23]$ and higher than that in Uganda [17], Chad and Benin [9]. The higher prevalence in Europe and United States of America (USA) can be attributed to the easier access of contraceptives, increased funding of policies, and interventions being implemented by these governments compared to Zambia [22, 24]. Furthermore, the higher gender equality in Europe compared to Zambia empowers women to make decisions regarding contraceptive use $[22,25,26]$.

Zambia's low adolescent contraceptive utilization rate risks negative progress towards achieving target 3.7 of sustainable development goal (SDG) three aimed at ensuring universal access to sexual and reproductive health-care services, including contraceptives by 2030 [27]. The current study showed that some predictors such as age and having a child were common in both rural and urban settings. However, their levels and the strength of their associations with utilization of modern contraceptives varied substantially across urban and rural areas. The strengths of associations were stronger among urban adolescents. Three predictors (marital status, wealth index and province) were significantly associated with modern contraceptives utilization in rural areas but not in urban areas. Zambia is among the subSaharan Africa countries with the lowest number of medical personnel (less than 1 doctor per 10,000 inhabitants) [28]. Rural Zambia has the highest shortage of qualified health personnel with facilities being often understaffed and under stocked with medical supplies including contraceptive methods which makes access to healthcare difficult and also limited choice of options [28, 29]. Limited availability of contraceptives in public facilities coupled with long distances covered reaching health facilities in rural areas unlike urban areas further limits contraceptives use in rural areas due to limited contraceptive choice, direct and indirect costs involved buying contraceptives from private facilities and transportation to facilities whose distances are usually far yet most rural residents are poorer than urban residents [29]. Increased availability and accessibility of contraceptives in urban areas coupled by the high number of adolescents in the richest quintile (48.3\%) compared $4.2 \%$ in rural areas and highest number of urban adolescents residing in Lusaka province the most developed region $31.4 \%$ compared to $3.6 \%$ for rural adolescents partly explains the significance of wealth index and province in rural Zambia. Hence there is need to bring services closer to adolescents in rural Zambia through strategies such as community health workers, increased incentives for health workers in rural areas, construction of more facilities and ensuring regular supply of medical commodities.

Older age (19 years) was associated with modern contraceptive utilization among both rural and urban adolescents compared to younger age ( 15 years). This association was stronger among urban adolescents compared to their rural counterparts. Older adolescents tend to be more exposed, knowledgeable and enlightened regarding availability and importance of contraceptives [5]. Furthermore, older age is associated with independence and better ability to make positive decisions about their health including contraception [1]. In addition, older adolescents are more likely to have had children, be married, and have obtained higher levels of education compared to their younger counterparts which factors have been documented to be positively associated with contraceptive utilization [5]. Older age has been shown to be associated with modern contraceptive utilization in similar studies $[2,5,30]$. 
Having had a child was associated with positive modern contraceptive utilization among both rural and urban adolescents compared to null parity. The study found that adolescents who had a child were more than 13 (in rural areas) and 18 (in urban areas) times more likely to practice contraceptive use compared to their counterparts who had no children. This might partly be attributed to improved health seeking behavioral which unfortunately comes in later after they have had a birth [17, 31]. Furthermore, adolescents that have had childbirth are more likely to utilize health facilities for antenatal care, delivery and post-natal care services [32] hence increased exposure to family planning counselling [17]. Childbirth has been documented to be associated with modern contraceptive utilization in similar studies $[17,31]$.

Marital status also had a positive relationship with modern contraceptives use among rural female adolescents. However, this was not observed among urban adolescents. Married or cohabiting adolescents were almost twice more likely to use contraceptives compared to their non-married counterparts. Married adolescents were almost twice more likely to utilize modern contraceptives compared to unmarried adolescents. This could be attributed to the increased financial and social support among married adolescents from their partners and in laws hence easier affordability and access to contraceptives compared to their unmarried counterparts $[5,17]$. Furthermore, married adolescents have regular exposure to sexual intercourse and the risk of unintended pregnancy hence more likely to use contraceptives [2]. Marital status has been shown to be associated with modern contraceptive use in similar contexts $[2,5,17,33]$.

Unlike in Urban areas, wealth index was associated with contraceptive utilization among rural adolescents. Adolescents in the richest wealth quintile were three times more likely to use contraception compared to their counterparts in the poorest quintile. This is consistent with findings from similar contexts $[1,17,30]$. Adolescents belonging to the poorest quintile are more likely to have limited access to modern contraceptives due to the direct and indirect costs incurred when accessing contraceptives [31, 34]. The poor are also more likely to be less informed about contraception due to the low education levels, less exposure to mass media which limits their health literacy and ability to make informed decisions [35-38]. Wealth has been shown to be associated with modern contraceptive use in other studies [31, 36, 39].

Province among rural adolescents was significantly associated with contraceptive utilization with adolescents in Luapula and Northern provinces being less likely to use contraceptives compared to those in the Western province. Luapula is among the provinces with the poorest health indicators such as the highest maternal mortality ratio attributable to the low quality of services, limited accessibility to care due to the associated costs worsened by the poor socio-economic situation in the province [40]. Furthermore health service delivery is affected by the limited numbers of health workers in these provinces with the Northern province having some of the highest doctor to population ratio and rural health centers' vacancy rates [41]. The poor socio-economic status affects access to quality education, exposure to mass media which coupled with poor quality of health services impends utilization of contraceptives among adolescents. Regional differences have similarly been shown to be associated with contraceptive use in various studies [31, 42-44]. 


\section{Strengths And Limitations}

We used a nationally representative sample and weighed the data for analysis and therefore our results are generalized to all Zambian female adolescents aged 15 to 19 years. Standardized procedures are a requirement of DHS surveys in data collection and validated questionnaires are used which ensures the internal and external validity of the results. However, use of cross-sectional data only enables associations to be established but not causal relationships.

\section{Conclusion}

This study demonstrates the considerable low prevalence of modern contraceptives utilization in rural and urban adolescents in Zambia using nationally representative data. Two factors (age and having a child) were found significant in both rural and urban areas while three (marriage, wealth index and province) were significant in only rural areas. This evidence suggests interventions aiming to increase contraceptive utilization should be context specific.

\section{Abbreviations}

AOR Adjusted Odds Ratio

Cl Confidence Interval

COR Crude Odds Ratio

DHS Demographic Health Survey

ZDHS Zambia Demographic Health Survey

OR Odds Ratio

SD Standard Deviation

WHO World Health Organization

SPSS Statistical Package for Social Science

\section{Declarations}

\section{Acknowledgements}

We thank the MEASURE DHS program for availing us with the data.

\section{Funding}

No funding was obtained for this study. 
Availability of data and materials

The data set used is openly available upon permission from MEASURE DHS website (URL: https://www.dhsprogram.com/data/available-datasets.cfm).

\section{Authors' contributions}

QS Conceived the idea, drafted the manuscript, performed analysis and interpreted the results. MWM, LMM and DM participated in the design of the study and helped in results interpretation and writing. All authors read and approved the final manuscript.

\section{Ethics approval and consent to participate}

High international ethical standards are ensured for MEASURE DHS surveys as ethical approval from the country is obtained from a national ethical review board and local authorities before implementing the survey and well-informed verbal consent is sought from the respondents prior to data collection. For the 2018 ZDHS, ethical approval was obtained from the Inner City Fund (ICF) and the Zambia Tropical Diseases Research Centre (TDRC), institutional review boards (IRBs) [13]. All methods of data collection were performed in accordance with the relevant guidelines and regulations [13]. This data set was obtained from the MEASURE DHS website (URL: https://www.dhsprogram.com/data/availabledatasets.cfm) after getting their permission and no formal ethical clearance was obtained since we conducted secondary analysis of publicly available data.

\section{Consent for publication}

Not applicable.

\section{Competing interests}

All authors declare that they have no competing interests.

\section{References}

1. Sidibé S, Delamou A, Camara BS, Dioubaté N, Manet H, El Ayadi AM, Benova L, Kouanda S: Trends in contraceptive use, unmet need and associated factors of modern contraceptive use among urban adolescents and young women in Guinea. BMC Public Health 2020, 20(1):1840.

2. Chola M, Hlongwana K, Ginindza TG: Patterns, trends, and factors associated with contraceptive use among adolescent girls in Zambia (1996 to 2014): a multilevel analysis. BMC Women's Health 2020, 20(1):185.

3. Kafle PP, Pakuryal KN, Regmi RR, Luintel S: Health problems and social consequences in teenage pregnancy in rural Kathmandu Valley. Nepal Medical College journal : NMCJ 2010, 12(1):42-44.

4. Ngome $\mathrm{E}$, Odimegwu C: The social context of adolescent women's use of modern contraceptives in Zimbabwe: a multilevel analysis. Reproductive Health 2014, 11(1):64. 
5. Nyarko SH: Prevalence and correlates of contraceptive use among female adolescents in Ghana. BMC Women's Health 2015, 15(1):60.

6. Yakubu I, Salisu WJ: Determinants of adolescent pregnancy in sub-Saharan Africa: a systematic review. Reprod Health 2018, 15(1):15.

7. Manzini N: Sexual initiation and childbearing among adolescent girls in KwaZulu Natal, South Africa. Reprod Health Matters 2001, 9(17):44-52.

8. Cleland J, Bernstein S, Ezeh A, Faundes A, Glasier A, Innis J: Family planning: the unfinished agenda. Lancet (London, England) 2006, 368(9549):1810-1827.

9. Ahinkorah BO, Hagan JE, Jr.: Female adolescents' reproductive health decision-making capacity and contraceptive use in sub-Saharan Africa: What does the future hold? 2020, 15(7):e0235601.

10. Dennis ML, Radovich E, Wong KLM, Owolabi O, Cavallaro FL, Mbizvo MT, Binagwaho A, Waiswa P, Lynch CA, Benova L: Pathways to increased coverage: an analysis of time trends in contraceptive need and use among adolescents and young women in Kenya, Rwanda, Tanzania, and Uganda. Reproductive Health 2017, 14(1):130.

11. de Vargas Nunes Coll C, Ewerling F, Hellwig F, de Barros AJD: Contraception in adolescence: the influence of parity and marital status on contraceptive use in 73 low-and middle-income countries. Reproductive Health 2019, 16(1):21.

12. White JS, Speizer IS: Can family planning outreach bridge the urban-rural divide in Zambia? BMC health services research 2007, 7:143-143.

13. Zambia Statistics Agency - ZSA, Ministry of Health - MOH, University Teaching Hospital Virology Laboratory - UTH-VL, ICF: Zambia Demographic and Health Survey 2018. In. Lusaka, Zambia: ZSA, MOH, UTH-VL and ICF; 2020.

14. Sserwanja Q, Mukunya D, Habumugisha T, Mutisya LM, Tuke R, Olal E: Factors associated with undernutrition among 20 to 49 year old women in Uganda: a secondary analysis of the Uganda demographic health survey 2016. BMC Public Health 2020, 20(1):1644.

15. DHS. The DHS program. https://www.dhsprogram.com/.

16. Namasivayam A, Lovell S, Namutamba S, Schluter PJ: Improved contraceptive use among women and men in Uganda between 1995-2016: A repeated cross-sectional population study. PLoS One 2019, 14(7):e0219963-e0219963.

17. Sserwanja Q, Musaba MW, Mukunya D: Prevalence and factors associated with modern contraceptives utilization among female adolescents in Uganda. BMC Women's Health 2021, 21(1):61.

18. Casey SE, Gallagher MC, Kakesa J, Kalyanpur A, Muselemu J-B, Rafanoharana RV, Spilotros N: Contraceptive use among adolescent and young women in North and South Kivu, Democratic Republic of the Congo: A cross-sectional population-based survey. PLoS medicine 2020, 17(3):e1003086.

19. Abrha S, Shiferaw S, Ahmed KY: Overweight and obesity and its socio-demographic correlates among urban Ethiopian women: evidence from the 2011 EDHS. BMC Public Health 2016, 16:636. 
20. Dankwah E, Zeng W, Feng C, Kirychuk S, Farag M: The social determinants of health facility delivery in Ghana. Reproductive Health 2019, 16(1):101.

21. Izugbara CO, Wekesah FM, Tilahun T, Amo-Adjei J, Tsala Dimbuene ZT. Family planning in East Africa: trends and dynamics. Nairobi, Kenya: African Population and Health Research Center (APHRC); 2018.

22. de Looze M, Madkour AS, Huijts T, Moreau N, Currie C: Country-Level Gender Equality and Adolescents' Contraceptive Use in Europe, Canada and Israel: Findings from 33 Countries. Perspect Sex Reprod Health 2019, 51(1):43-53.

23. Scott RH, Wellings K, Lindberg L: Adolescent Sexual Activity, Contraceptive Use, and Pregnancy in Britain and the U.S.: A Multidecade Comparison. Journal of Adolescent Health 2020, 66(5):582-588.

24. Ooms GI, Kibira D, Reed T, van den Ham HA, Mantel-Teeuwisse AK, Buckland-Merrett G: Access to sexual and reproductive health commodities in East and Southern Africa: a cross-country comparison of availability, affordability and stock-outs in Kenya, Tanzania, Uganda and Zambia. BMC Public Health 2020, 20(1):1053.

25. Spichiger, Rachel, and Edna Kabala. Gender Equality and Land Administration: the Case of Zambia. Danish Institute for International Studies, 2014, www.jstor.org/stable/resrep13368. Accessed 5 Mar. 2021.

26. African Impact. Gender Equality in Zambia: The Journey of Girl Impact. https://africanimpact.com/journey-of-girl-impact-zambia/.

27. WHO.SDG 3: Ensure healthy lives and promote wellbeing for all at all ages.https://www.who.int/sdg/targets/en/.

28. Haaland MES, Haukanes H, Zulu JM, Moland KM, Blystad A: Silent politics and unknown numbers: Rural health bureaucrats and Zambian abortion policy. Social Science \& Medicine 2020, 251:112909.

29. Almonte MT, Lynch CA: Impact of internal female migration on unmet need for modern contraception in Zambia. Reproductive health 2019, 16(1):169-169.

30. Hounton S, Barros AJD, Amouzou A, Shiferaw S, Maïga A, Akinyemi A, Friedman H, Koroma D: Patterns and trends of contraceptive use among sexually active adolescents in Burkina Faso, Ethiopia, and Nigeria: evidence from cross-sectional studies. Global health action 2015, 8:2973729737.

31. Kabagenyi A, Habaasa G, Rutaremwa G: Low Contraceptive Use among Young Females in Uganda: Does Birth History and Age at Birth have an Influence? Analysis of 2011 Demographic and Health Survey. J Contracept Stud 2016, 1(1):4.

32. Uganda Bureau of Statistics - UBOS, ICF: Uganda Demographic and Health Survey 2016. In. Kampala, Uganda: UBOS and ICF; 2018.

33. Appiah F, Seidu A-A, Ahinkorah BO, Baatiema L, Ameyaw EK: Trends and determinants of contraceptive use among female adolescents in Ghana: Analysis of 2003-2014 Demographic and Health Surveys. SSM - population health 2020, 10:100554-100554. 
34. Prata N: Making family planning accessible in resource-poor settings. Philos Trans $R$ Soc Lond B Biol Sci 2009, 364(1532):3093-3099.

35. Rios-Zertuche D, Blanco LC, Zúñiga-Brenes P, Palmisano EB, Colombara DV, Mokdad AH, Iriarte E: Contraceptive knowledge and use among women living in the poorest areas of five Mesoamerican countries. Contraception 2017, 95(6):549-557.

36. Kumar M, Meena J, Sharma S, Poddar A, Dhalliwal V, Modi-Satish Chander Modi SC, Singh K: Contraceptive Use Among Low-Income Urban Married Women in India. The Journal of Sexual Medicine 2011, 8(2):376-382.

37. Bardaweel SK, Akour AA, Alkhawaldeh A: Impediments to use of oral contraceptives among refugee women in camps, Jordan. Women \& health 2019, 59(3):252-265.

38. Bardaweel SK, Akour AA, Kilani M-VZ: Current knowledge, attitude, and patterns of oral contraceptives utilization among women in Jordan. BMC Women's Health 2015, 15(1):117.

39. Tekelab T, Melka AS, Wirtu D: Predictors of modern contraceptive methods use among married women of reproductive age groups in Western Ethiopia: a community based cross-sectional study. BMC Women's Health 2015, 15(1):52.

40. Chibuye PS, Bazant ES, Wallon M, Rao N, Fruhauf T: Experiences with and expectations of maternity waiting homes in Luapula Province, Zambia: a mixed-methods, cross-sectional study with women, community groups and stakeholders. BMC pregnancy and childbirth 2018, 18(1):42.

41. Ferrinho P, Siziya S, Goma F, Dussault G: The human resource for health situation in Zambia: deficit and maldistribution. Human Resources for Health 2011, 9(1):30.

42. Asresie MB, Fekadu GA, Dagnew GW: Contraceptive use among women with no fertility intention in Ethiopia. PLoS One 2020, 15(6):e0234474.

43. Kungu W, Agwanda A, Khasakhala A: Trends and determinants of contraceptive method choice among women aged 15-24 years in Kenya [version 1; peer review: 1 approved with reservations]. F1000Research 2020, 9(197).

44. Mahmud M, Islam MM: Adolescent contraceptive use and its determinants in Bangladesh: evidence from Bangladesh Fertility Survey 1989. Contraception 1995, 52(3):181-186.

\section{Supplementary Files}

Supplementary files 1 and 2 are not available with this version. 